INTERNATIONAL JOURNAL OF MULTIDISCIPLINARY RESEARCH AND ANALySis

ISSN(print): 2643-9840, ISSN(online): 2643-9875

Volume 05 Issue 02 February 2022

DOI: 10.47191/ijmra/v5-i2-20, Impact Factor: 6.072

Page No. $372-380$

\title{
Customer Satisfaction among Nursing Officers: Experience of Service Recipients at a District Health Office in Sri Lanka
}

\author{
Rajakaruna, I.M.S.M ${ }^{1}$, Bandara T.W.M.A.J ${ }^{2}$, Ponweera, P.A.D.D. ${ }^{3}$, Dharmagunawardane, $\mathrm{D}^{4}$, \\ Arnold, S.M ${ }^{5}$ \\ $1,2,3,4,5$ Ministry of Health, Sri Lanka
}

\begin{abstract}
Introduction: Customer satisfaction, efficiency and effectiveness are key essential characteristics of good service delivery. Unacceptable delays in providing services and subsequent re-visits had created customer dissatisfaction with services provided by the Regional Director of Health Services' Office, Kurunegala. A descriptive cross-sectional study was conducted to assess the current levels of customer satisfaction, efficiency and effectiveness of service provision to nursing officers at the Regional Director of Health Services' Office, Kurunegala.

Methods: Ten services offered to nursing officers from Establishment Branch were prioritized for the assessment. The research adopted mixed methods and involved a customer survey, a desk review, key informant interviews and focus group discussions.

Proportions, percentages and means were calculated for quantitative data and $z$ test for percentages was applied as appropriate. The $p$-value $<0.05$ was considered significant. Narrative analysis was done for qualitative data.

Results: Major deficiencies identified were non-availability of service standards, ineffective two-way communication and submitting incomplete documents by applicants. Compliance of nursing officers' files with service standards was $40 \%$. It was revealed that $56.6 \%$ of nursing officers had to revisit on average 2.4 times to receive the requested service. Only $11.5 \%$ of nursing officers were satisfied with the service provision. Suggested solutions include complying with developed service standards, establishing an effective feedback response system, developing document submission checklists, format compilations and a booklet on work steps.

Conclusions: The customer satisfaction, efficiency and effectiveness of services to nursing officers at RDHSK was unsatisfactory. It is recommended to implement interventions to improve service delivery by the Establishment Branch of RDHSK for healthcare staff category-wise.
\end{abstract}

KEYWORDS: Efficiency, Effectiveness, Services, Nursing officers, Establishment Branch, Regional Director of Health Services' Office.

\section{INTRODUCTION}

The Office of Regional Director of Health Services is the administrative focal point for health institutions including hospitals (ranging from large to small) and Medical Officer of Health (MOH) Offices offering comprehensive public health services in each district of Sri Lanka. The Office of Regional Director of Health Services, Kurunegala (RDHSK) is the administrative focal point for Kurunegala District and has four branches. Out of which, the Establishment Branch (EB) has the largest external customer interface of 5044 health workers in 63 categories of 129 health institutions coming under the directorate. ${ }^{1}$ It deals with routine but critical personal file-related services. Consequently, catering with efficient and effective services to the satisfaction of a large number of service recipients using limited resources has been a challenge for the management of RDHSK.

Lack of explicit service standards for the EB of RDHSK results in unacceptable delays in service provision and frequent unwarranted visits by the service users. Ineffective two-way communication between the EB and service using healthcare staff builds a dilemma among service users on documents that need to be submitted along with service requests, which adds up to the delay. Besides, there is no existing mechanism to tackle service users' grievances on poor service provision. These factors collectively create dissatisfaction among service users of EB. Therefore, the assessment of the current levels of customer 


\section{Customer Satisfaction among Nursing Officers: Experience of Service Recipients at a District Health Office in Sri Lanka}

satisfaction, efficiency and effectiveness of service provision to the healthcare staff at the EB of RDHSK is important to identify deficiencies and thereby to improve customer satisfaction by devising well-targeted and effective initiatives.

Customer satisfaction is defined as a measurement that determines how happy customers are with a company's products, services, and capabilities. An organization's main focus must be to satisfy its customers regardless of being profitable or not. Customer satisfaction information can help an institution determine how to best improve its products and services. Organizations should not assume that they know what the customers want. Instead, it is important to understand the true voice of customers, using tools such as customer surveys, focus groups, and polling. Organizations can gain detailed insights on what the customers want through such tools and better tailor their services or products to meet or exceed customer expectations. ${ }^{2}$ Efficiency and effectiveness are key essential characteristics of good service delivery. Effectiveness is the extent to which an activity fulfils its intended purpose or function whereas efficiency is the extent to which an activity achieves its goal whilst minimizing resource usage. ${ }^{3}$ Peter Drucker defines 'Effectiveness is doing the right things; efficiency is doing things right'. ${ }^{4}$ Ineffective and inefficient processes are costly in terms of money, delays and customer dissatisfaction. ${ }^{5}$ Organizations can be assessed from either an efficiency or effectiveness perspective. Efficiency measures how successfully the inputs have been transformed into outputs without waste. Effectiveness measures the degree to which a business achieves its goals. Having a clear view of current organizational effectiveness and customer expectations is a critical success factor. ${ }^{6}$ Organizational efficiency reflects the improvement of the internal processes of the organization. ${ }^{7}$ Improving the quality of service delivery is a challenge in many developing countries. Moreover, traditional systems of administration have failed to respond to the citizens' quest for efficient and effective public service delivery. ${ }^{8}$ Process mapping is a way of reviewing existing processes for improving them for maximum efficiency and effectiveness. ${ }^{9}$

A service standard helps to define what a customer can expect from a service and how the service should be delivered by the service provider such as in terms of timeliness, accuracy and suitability. ${ }^{13}$ Service standards have two main goals: Establish yield objectives for employees and inform the customer about what they have the right to expect. When clearly stated, service standards equip the personnel with the right tools to bring about the service recipient satisfaction and facilitate engagement of the service provider. ${ }^{14}$

\section{METHODS}

A descriptive cross-sectional study was conducted during August 2019 at the Establishment Branch to assess the customer satisfaction, efficiency and effectiveness of service provision to nursing officers by the Establishment Branch of Regional Director of Health Services' Office, Kurunegala.

As the processes of personal file related services were unique for each healthcare staff category, the assessment of the efficiency and effectiveness of services need to be specific to each healthcare staff category. Based on the size of the customer interface, the volume of issues faced by the service providers and project feasibility, the category of nursing officers was chosen for the assessment. The topmost seven services resulting in $81.9 \%$ of visits of nursing officers to EB were identified based on the data gathered from nursing officers. Those services included obtaining the formal letter of appointment, registration under the widows' /widowers' \& orphans' pension scheme, approving an annual increment, confirmation in the service, Grade II promotion, Grade I promotion and Supra Grade promotion. Another three services being provided to nursing officers i.e.: obtaining foreign leave, prior approval for retirement and retirement were identified by the RDHSK staff based on the urgency, importance and volume of issues faced by them. Those ten services were prioritized for assessing the current level of efficiency and effectiveness of service provision.

A core group of seven members consisting of four Management Assistants providing services to nursing officers at EB, the Senior Management Assistant, the Administrative Officer and the Deputy Regional Director of Health Services was formed for developing service standards through re-designing of processes. The routine process of providing the selected services was mapped by the principal investigator using qualitative data gathered through observation, Key Informant Interviews (KII) and Focus Group Discussion (FGD) held with service providers of RDHSK who take part in each process. The process extended from the point of collecting the documents by the RDHSK staff from the applicant nurse up to the receipt of completion or rejection letter by the applicant. The workflow of the services was drawn up considering preparations, recommendations, certifications, approvals etc. along with the officers responsible for each point. Then the processes were studied extensively by the core group to identify deficiencies in service provision. The delays between points were identified and the possible ways to minimize delays were examined. The possibilities for delegation were considered. Repetitions and redundant steps were eliminated. Quality requirements to be met at each point were identified. Finally, the core group came up with a redesigned process. The time required between points of the workflow was assessed keeping a margin for service contingencies. Then the total time duration 


\section{Customer Satisfaction among Nursing Officers: Experience of Service Recipients at a District Health Office in Sri Lanka}

needed to deliver each service in days was calculated to set service standards. Nursing officers receiving services from RDHSK and the staff of RDHSK providing services to nursing officers were consulted on the total time duration needed to deliver each service (service standard) before finalizing it.

The current research adopted a mixed-method approach. Key Informant Interviews, Focus Group Discussions, a desk review and a customer survey were used for collecting data. The customers were surveyed using an interviewer-administered questionnaire which consisted of open and closed-ended questions. The face validity and content validity of the questionnaire were ensured through reviewing literature and discussions with relevant stakeholders and experts in the field including a Consultant Community Physician and a Consultant Medical Administrator. The survey aimed to assess the several important socio-demographic variables of participant nursing officers, service/s the participants were seeking and the number of visits made to receive each service from the EB of RDHSK, service expectations of nursing officers when receiving services from EB, nursing officers' satisfaction on selected attributes of service provision from EB and their suggestions for service improvements. The entire population of nursing officers $(n=122)$ who visited EB and completed receiving prioritized service/s for four consecutive Wednesdays, which were public days, were surveyed using a structured interviewer-administered questionnaire. Hence, no sampling method was adopted. A convenient sample $(n=50)$ of personal files of nursing officers from files that had been completed in the selected services (five files per service) during a month was chosen for the desk review. The checklist used in desk review assessed the number of personal files that complied with the set service standards. The KIls and FGDs were conducted to identify issues faced by service providers of RDHSK in providing services at EB to nursing officers and to probe their suggestions for service improvements. The KIls were held with the Regional Director of Health Services, the Deputy Regional Director of Health Services, the Medical

Officer of Quality Management Unit and the Administrative Officer of the RDHSK using a structured interviewer guide. Two FGDs were conducted with service providers who involve in providing selected services to nursing officers at EB of the RDHSK using an FGD guide. The Senior Management Assistant, Management Assistants $(n=6)$ providing prioritized services at EB, and the Management Assistant and the Health Activity Assistant at Tappal of RDHSK took part in discussions. The KIls and FGDs were conducted by the principal investigator.

Quantitative data were analyzed using Statistical Package for Social Sciences (SPSS) software. The proportions, percentages and means were calculated where appropriate. The statistical significance of the differences in nursing officers' service expectations and their satisfaction was analyzed by applying the two-sample $z$ test for percentages. The $p$-value $<0.05$ was considered as the level of significance. The KIIs and FGDs were electronically recorded with the participant's consent and transcribed. Narrative analysis was done for qualitative data. Ethics clearance for the study was obtained from the Ethics Review Committee of the Faculty of Medicine, the University of Colombo following approval of the Board of Study in Medical Administration. Administrative approvals were obtained from the Provincial Director of Health Services of North-Western Province and the Regional Director of Health Services of Kurunegala District before starting the study. Informed consent was obtained from all participants. The confidentiality and anonymity of study participants were preserved. The principal investigator carried out data collection and closely monitored the process to assure reliability. The principal investigator had no affiliations with or involvement in any organization or entity with any financial or non-financial interest in the subject materials discussed in this research.

\section{RESULTS}

Overall, the customer satisfaction, current level of efficiency and effectiveness of providing services to nursing officers at the EB of RDHSK was found to be unsatisfactory. The findings of the quantitative and qualitative components are outlined below.

\section{Quantitative results}

Quantitative data were gathered through the customer survey, checklist and the quantitative elements of KIls and FGDs.

Based on the quantitative data gathered from the customer survey, the frequency distribution of services visited by nursing officers at EB is listed in table1.

Table 1: Distribution by services visited by nursing officers at Establishment Branch

\begin{tabular}{|l|l|l|l|l|}
\hline & Service & Frequency & Percentage & $\begin{array}{l}\text { Cumulative } \\
\text { percentage }\end{array}$ \\
\hline 1 & Annual increment & 40 & 32.8 & 32.8 \\
\hline 2 & Registration for widows'/ widowers' \& orphans' pension scheme & 37 & 30.3 & 63.1 \\
\hline 3 & $\begin{array}{l}\text { Grade promotions } \\
\text { (Grade I, II \& Supra Grade) }\end{array}$ & 12 & 9.8 & 72.9 \\
\hline
\end{tabular}


Customer Satisfaction among Nursing Officers: Experience of Service Recipients at a District Health Office in Sri Lanka

\begin{tabular}{|l|l|l|l|l|}
\hline 4 & Service confirmation & 07 & 5.7 & 78.6 \\
\hline 5 & Formal appointment letter & 04 & 3.3 & 81.9 \\
\hline 6 & Maternity leave & 03 & 2.4 & 84.3 \\
\hline 7 & Others & 19 & 15.7 & 100.0 \\
\hline & Total & 122 & 100.0 & 100.0 \\
\hline
\end{tabular}

The services that needed $81.9 \%$ of visits by nursing officers to EB were prioritized for the assessment.

The service standards of prioritized ten services that were developed following process mapping and redesigning are as below (Table 2).

Table 2: Service standards for the prioritized ten services offered to nursing officers

\begin{tabular}{|c|c|c|}
\hline & Service & Service standard \\
\hline 1 & $\begin{array}{l}\text { Forwarding the request for obtaining the formal letter of appointment to the } \\
\text { Provincial Director of Health Services' office }\end{array}$ & 02 days \\
\hline 2 & $\begin{array}{l}\text { Forwarding the request for registration under the widows'/widowers' \& orphans' } \\
\text { pension scheme to the Provincial Director of Health Services' office }\end{array}$ & 02 days \\
\hline 3 & $\begin{array}{l}\text { Forwarding the approval of annual increments to the Salary Branch of the } \\
\text { Regional Director of Health Services' office }\end{array}$ & 05 days \\
\hline 4 & $\begin{array}{l}\text { Forwarding the request for confirmation of the service to the Provincial Director of } \\
\text { Health Services' office }\end{array}$ & 07 days \\
\hline 5 & $\begin{array}{l}\text { Forwarding the request for the promotion from Grade III to Grade II to the } \\
\text { Provincial Director of Health Services' office }\end{array}$ & 07 days \\
\hline 6 & $\begin{array}{l}\text { Forwarding the request for the promotion from Grade II to Grade I to the } \\
\text { Provincial Director of Health Services' office }\end{array}$ & 04 days \\
\hline 7 & $\begin{array}{l}\text { Forwarding the request for the promotion from Grade I to Supra Grade to the } \\
\text { Provincial Director of Health Services' office }\end{array}$ & 04 days \\
\hline 8 & $\begin{array}{l}\text { Forwarding the request for recommending foreign leave with full pay } \\
\text { (personal/duty) to the Provincial Director of Health Services' office }\end{array}$ & 03 days \\
\hline 9 & $\begin{array}{l}\text { Forwarding the request for obtaining the prior approval for retirement to the } \\
\text { Provincial Director of Health Services' office }\end{array}$ & 10 days \\
\hline 10 & Forwarding the PD 03 format to the Pensions Department & 14 days \\
\hline
\end{tabular}

Table 3 shows the quantitative results of desk review, selected quantitative results of the survey, and quantitative results of KIls and FGDs.

Of the files, $40 \%$ complied with service standards of prioritized services. Among nursing officers $56.6 \%$ revisited the RDHSK for receiving prioritized service/s. A nursing officer on average had to pay 2.4 visits per service to the RDHSK to get the requested service completed. Three out of 13 service providers were satisfied with the level of efficiency and effectiveness of providing prioritized services to nursing officers at EB.

Table 3: Key findings of the desk review, survey, KIls and FGDs

\begin{tabular}{|l|l|l|}
\hline & Indicator & Result \\
\hline 1. & Percentage of files complying with service standards of prioritized services & 40.0 \\
\hline 2. & Percentage of nursing officers revisited the RDHSK for receiving prioritized service/s & 56.6 \\
\hline 3. & The average number of visits to RDHSK per service to get the requested service & 2.4 \\
\hline 4. & $\begin{array}{l}\text { The proportion of service providers satisfied with the level of efficiency and effectiveness of } \\
\text { providing prioritized services to nursing officers at EB }\end{array}$ & $3 / 13$ \\
\hline
\end{tabular}




\section{Customer Satisfaction among Nursing Officers: Experience of Service Recipients at a District Health Office in Sri Lanka}

The difference between nursing officers' service expectations and satisfaction over the selected service attributes at EB were tested statistically to find out the attributes that do not meet the service expectations. The results are as in table 4.

Table 4: Distribution of nursing officers' service expectations and satisfaction on selected service attributes

\begin{tabular}{|c|c|c|c|c|}
\hline & Attribute & $\begin{array}{l}\text { Expectation (P) } \\
\mathrm{N}=122\end{array}$ & $\begin{array}{l}\text { Satisfaction (P) } \\
\mathrm{N}=122\end{array}$ & $\begin{array}{l}\text { Statistical } \\
\text { significance }\end{array}$ \\
\hline 1. & $\begin{array}{l}\text { Awareness of all documents required with a } \\
\text { service request }\end{array}$ & $\begin{array}{l}100.0 \\
(122 / 122)\end{array}$ & $\begin{array}{l}0.0 \\
(0 / 122)\end{array}$ & $\begin{array}{l}z=-15.62 \\
p<0.001\end{array}$ \\
\hline 2. & $\begin{array}{l}\text { Awareness of the place of formats can be } \\
\text { obtained }\end{array}$ & $\begin{array}{l}41.8 \\
(51 / 122)\end{array}$ & $9.0(11 / 122)$ & $z=5.88 p<0.001$ \\
\hline 3. & $\begin{array}{l}\text { Awareness of duration required to deliver the } \\
\text { services }\end{array}$ & $\begin{array}{l}100.0 \\
(122 / 122)\end{array}$ & $\begin{array}{l}1.6 \\
(2 / 122)\end{array}$ & $\begin{array}{l}z=15.366 \\
p<0.001\end{array}$ \\
\hline 4. & $\begin{array}{l}\text { Immediate notification in delay (If relevant } \\
\text { only) }\end{array}$ & $\begin{array}{l}100.0 \\
(122 / 122)\end{array}$ & $\begin{array}{l}0.0 \\
(0 / 122)\end{array}$ & $z=15.62 p<0.001$ \\
\hline 5. & $\begin{array}{l}\text { Availability of contact details of the responsible } \\
\text { officer }\end{array}$ & $\begin{array}{l}59.8 \\
(73 / 122)\end{array}$ & $\begin{array}{l}60.6 \\
(74 / 122)\end{array}$ & $z=-0.13 p>0.001$ \\
\hline 6. & Complaints handling (If relevant only) & $\begin{array}{l}98.4 \\
(120 / 122)\end{array}$ & $\begin{array}{l}0.0 \\
(0 / 122)\end{array}$ & $\begin{array}{l}z=15.36 \\
P<0.001\end{array}$ \\
\hline 7. & Promptness of service delivery & $\begin{array}{l}100.0 \\
(122 / 122)\end{array}$ & $\begin{array}{l}22.1 \\
(27 / 122)\end{array}$ & $z=12.47 p<0.001$ \\
\hline 8. & Easiness of getting services & $\begin{array}{l}100.0 \\
(122 / 122)\end{array}$ & $\begin{array}{l}4.1 \\
(5 / 122)\end{array}$ & $z=14.99 p<0.001$ \\
\hline 9. & Courtesy of staff & $\begin{array}{l}53.2 \\
(65 / 122)\end{array}$ & $9.8(12 / 122)$ & $z=7.30 p<0.001$ \\
\hline 10. & Overall satisfaction & & $\begin{array}{l}11.5 \\
(14 / 122)\end{array}$ & \\
\hline
\end{tabular}

P=Proportion

Service expectations of nursing officers were $100 \%$ for the attributes of being aware in advance of all documents required with a service request, being aware of the time taken to deliver services, immediate notification in delays, promptness of service delivery and easiness of getting services. The complaints handling was also expected by $98.4 \%(n=120)$ of participant nursing officers. The remaining attributes of availability of contact details of the responsible officer, courtesy of the RDHSK staff and awareness in advance of the place of formats were expected by $59.8 \%(n=73), 53.2 \%(n=65)$ and $41.8 \%(n=51)$ of participants respectively.

Among nursing officers, $11.5 \%(n=14)$ were satisfied with service provision at EB overall. The current level of satisfaction on three attributes (awareness in advance of all documents required with a service request, immediate notification in delay and complaints handling) was zero. Availability of contact details of the responsible officer showed the highest satisfaction which was $60.6 \%$ $(n=74)$. The promptness of service delivery, courtesy of staff, awareness in advance of the place of formats, easiness of getting services and awareness of time taken to deliver services demonstrated $22.1 \%(n=27), 9.8 \%(n=12), 9.0 \%(n=11), 4.1 \%(n=5)$ and $1.6 \%(n=2)$ of satisfaction respectively. Significant differences $(p<0.001)$ were observed between the nursing officers' service expectations and the satisfaction on all service attributes except for the attribute 'Availability of contact details of responsible officer'.

Nursing officers' service expectations were compared with their satisfaction on selected service attributes of EB and depicted below (Figure 1). 


\section{Customer Satisfaction among Nursing Officers: Experience of Service Recipients at a District Health Office in Sri}

Lanka

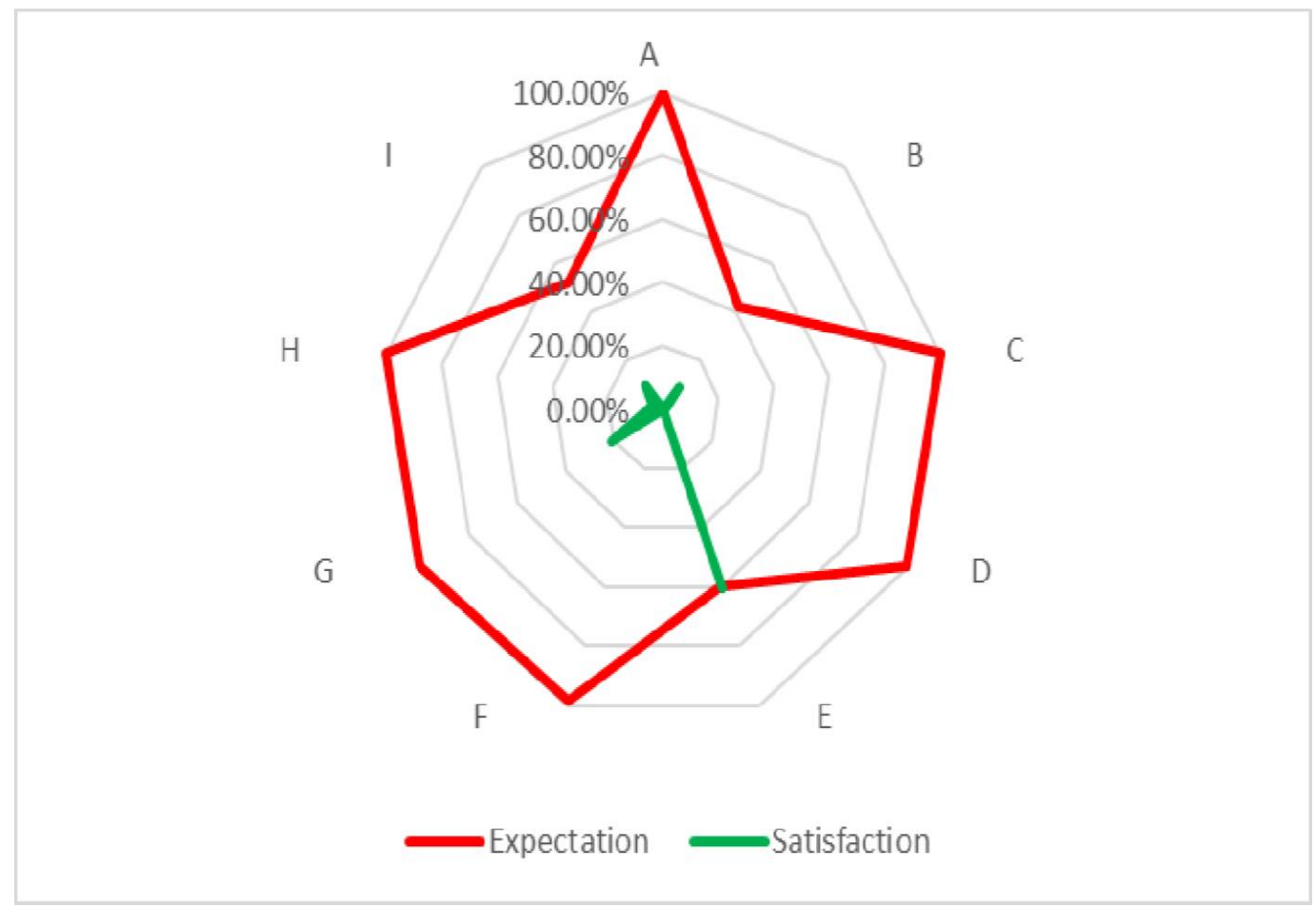

Figure 1: Comparison of nursing officers' expectations with nursing officers' satisfaction on service attributes

There was a considerable gap between the nursing officers' expectations and their current level of satisfaction except for the 'Availability of contact details of responsible officer'.

\section{Qualitative Results}

Qualitative inputs of KIIs, FGDs and the customer survey combined with mapping the process of providing services to nursing officers at EB identified the following deficiencies. There were no explicit service standards for the services offered to nursing officers and therefore the time to deliver services was unacceptably long and varied. Applicants had to visit the EB several times for follow up. The two-way communication between RDHSK and applicant nursing officers was not satisfactory. The applicants were not aware of the documents and other requirements that need to be fulfilled for receiving the required service/s. Nursing officers had to visit the RDHSK to collect application formats then and there they need those. The subject officers accepted requests without checking the completeness of documents and they had no mechanism of referring lengthy lists of documents for crosschecks. Missing or incompleteness of one or more documents resulted in rework and added up to the delay. When a subject officer is on leave, the covering up officer does not know the work steps to be followed. On top of that, the grievances of nursing officers were not appropriately dealt with by the RDHSK staff, and nursing officers' suggestions were never sought for service improvements.

The suggestions for service improvements gathered from nursing officers through the customer survey and service providers of RDHSK through KIIs and FGDs combined with process mapping identified the following solutions to improve the efficiency and effectiveness of providing services to nursing officers at EB of RDHSK.

1. Publicizing of and adhering to developed service standards in providing prioritized ten services to nursing officers at EB

2. Implementing an effective feedback and response system to redress nursing officers' grievances on service inefficiencies at EB and utilizing received suggestions for improving services offered to nursing officers at RDHSK

3. Developing document submission checklists based on the required documents to be filled for receiving services by applicant nurses

4. Compilation of formats to be filled by applicants for each service with the relevant checklist on the top and making compilations available at nursing officers' work institutions

5. Developing a booklet incorporating redesigned work steps for prioritized ten services to be followed by subject officers and covering up officers at the EB 


\section{Customer Satisfaction among Nursing Officers: Experience of Service Recipients at a District Health Office in Sri Lanka}

\section{DISCUSSION}

This descriptive cross-sectional study aimed at assessing the customer satisfaction, efficiency and effectiveness of providing services to the nursing staff at the RDHSK. Ten services offered to nursing officers by the Establishment Branch (EB) of RDHSK were prioritized for the assessment.

This study adopted mixed methods for understanding the contradictions between quantitative results and qualitative findings if any. An interviewer-administered questionnaire was preferred over a self-administered one as the respondents might need clarifications about items in the questionnaire, especially in the service attributes section. Process mapping, a way of reviewing existing processes for improving them for maximum efficiency and effectiveness was combined with qualitative and quantitative data to identify deficiencies in service provision to nursing officers at EB.

The services that are mostly ineffective and inefficient were prioritized for inclusion in the assessment. Service standards in terms of days that take to complete each service were calculated as there were no nationally accepted norms for referring. The majority of services in the prioritized list cannot be completed within the RDHSK and need forwarding to the Provincial Director of Health Services' office for completing the rest of the steps.

The checklist data showed that only a minority of files as low as $40 \%$ complied with service standards. According to the survey data, a majority $(56.6 \%)$ of nursing officers revisited the RDHSK for receiving intervened service/s. Non-availability of service standards, ineffective two-way communication between service receivers and providers, and submitting incomplete documents resulted in delayed personal file-related services and repeat visits by nurses. Hence, an applicant nurse had to pay on average 2.4 visits to RDHSK per service to complete getting the requested service. The number of service providers satisfied with providing services to nursing officers at EB was calculated using the qualitative data gathered from KIIs and FGDs. Only a very few service providers, three out of 13 , was satisfied with the level of efficiency and effectiveness of service provision to nursing officers at the EB. They were aware of the inefficiencies in service provision and seeking for solutions to rectify them by the time of assessment. A section on nursing officers' service expectations was incorporated into the survey questionnaire as a means of a needs assessment. Out of the nine service attributes used to assess the service expectations, five attributes which are awareness in advance of all documents required with a service request, awareness of time taken to deliver services, immediate notification in delay, promptness of service delivery, and easiness of getting services were expected by all $(100 \%, n=122)$ participants. The attribute 'proper complaints handling' was expected by $98.4 \%(n=120)$ of service recipients. Those needs highlight the nursing officers' quest for receiving efficient and effective services from EB. The remaining attributes i.e.: awareness in advance of the place of formats, availability of contact details of the responsible officer and the courtesy of staff were expected by a relatively lesser number of participants. Availability of contact details of the responsible officer to be contacted in a service need was expected by $59.8 \%(n=73)$ of nursing officers as most of them had contact details of EB and RDHSK before the assessment. A $53.2 \%$ $(n=65)$ of nursing officers expected the RDHSK staff to be courteous while providing services to them. The rest thought that the timeliness matters over the courtesy. Being aware in advance of the place of formats scored the minimum expectation of $41.8 \%(n=51)$ and the rest did not expect to be aware of the place of formats as they knew traditionally those were kept at RDHSK. The nursing officers' satisfaction on the same selected service attributes at EB was assessed. Satisfaction of nurses on all attributes except attribute 'availability of contact details of the responsible officer' showed a very low score (Table 4). Among them, three attributes namely awareness in advance of all documents required with a service request, immediate notification in delay when relevant, complaints handling reported zero satisfaction. It reflects the poor awareness of nursing officers in advance of the documents required with a service request and the non-availability of mechanisms at RDHSK for immediately notifying in a delay and handling complaints of service users. The attribute 'availability of contact details of the responsible officer' showed the highest satisfaction of $60.6 \%(n=74)$ because most of the nursing officers had contact numbers of EB and RDHSK both even though contacting them gave them no relief for the issues faced. The remaining service attributes that include awareness in advance of the place of formats, awareness of the time taken to deliver services, promptness of service delivery, easiness of getting services and courtesy of the RDHSK staff resulted in very low satisfaction scores. It is a result of poor awareness in advance of the place of formats, poor awareness of services delivery standards, delays in completing nursing officers' service requests, overall difficulty in getting services and issues in the courtesy of the serving staff of RDHSK. The overall satisfaction was very low $(11.5 \%, n=14)$ owing to the poor satisfaction on service attributes described above. The non-availability of support personnel to contact in difficulty in getting services, not seeking nurses' suggestions for service improvements and need to visit RDHSK for collecting the required formats when a service is required had an impact on the poor overall satisfaction. The difference between the satisfaction of nursing officers and their expectations was statistically significant for all attributes except attribute 'availability of contact details of the responsible officer' proving the deficiencies in efficiency and effectiveness of the services offered to healthcare staff by the RDHSK. 


\section{Customer Satisfaction among Nursing Officers: Experience of Service Recipients at a District Health Office in Sri Lanka}

Kotler et al. ${ }^{15}$ describe satisfaction as a feeling that surfaces from an evaluation process when the consumer compares what is received against what is expected from the utilization. Therefore, nursing officers' expectations on service provision were compared with satisfaction to identify further gaps. It was evident that all attributes except one (availability of contact details of responsible officer) had expectation-perception gaps (Figure 1) that need to be bridged through appropriate interventions.

Attribute 'availability of contact details of the responsible officer' yielded slightly greater satisfaction $(60.6 \%)$ than expectation (59.8\%) because most of them had the contact details of EB and RDHSK even though contacting them was not fruitful.

The study found issues of non-availability of service standards, ineffective two-way communication between service receivers and providers, and submitting incomplete documents which resulted in delayed personal file-related services and repeat visits by nursing officers leading to external customer dissatisfaction. The suggestions of the service receivers and service providers identified specific solutions to each issue.

\section{CONCLUSIONS}

The customer satisfaction, efficiency and effectiveness of providing services to the nursing officers at RDHSK were found to be unsatisfactory primarily due to the non-availability of explicit service standards, ineffective two-way communication between RDHSK and applicants, and submission of incomplete documents for receiving services with special reverence to services provided to nursing officers at EB. The solutions suggested by the service receivers and service providers for the identified issues include complying with service standards set for prioritized services being offered to nursing officers at EB of RDHSK, developing an effective feedback and response system, welcoming suggestions of nursing officers for service improvements, developing lists of the document and other requirements that need to be fulfilled for receiving the service/s and then document submission checklists, compiling formats to be filled by applicants with the relevant checklist on the top and making them available at their workplaces, and developing a booklet on redesigned work steps to be followed by subject officers and covering up officers at the EB.

\section{REFERENCES}

1) Ministry of Health, Sri Lanka. Annual Health Statistics 2019, Sri Lanka [Internet]. 2021. Available from: http://www.health.gov.lk/moh_final/english/public/elfinder/files/publications/AHB/AHS\%202019.pdf

2) What is Customer Satisfaction? | ASQ [Internet]. Learn about quality. 2022 [cited 2022 Feb 8]. Available from: https://asq.org/quality-resources/customer-satisfaction

3) Harvey L. Analytic quality glossary, Quality Research International [Internet]. 2021 [cited 2021 Oct 30]. Available from: http://www.qualityresearchinternational.com/glossary/

4) Goldstein D. Peter Drucker: Is it better to be effective or efficient? [Internet]. Rich As A King. 2016 [cited 2021 Oct 30]. Available from: https://www.richasaking.com/peter-drucker-is-it-better-to-be-effective-or-efficient/

5) Cambridge University Press. external customer [Internet]. 2021 [cited 2021 Oct 30]. Available from: https://dictionary.cambridge.org/dictionary/english/external-customer

6) Ambrož M, Martina P. Organisational effectiveness and customer satisfaction. Organizacija [Internet]. 2008 Dec 1;41:161- 73. Available from: https://www.researchgate.net/publication/227640576_Organisational_Effectiveness_and_Customer_Satisfaction

7) Bartuševičienè I, Šakalytė E. Organizational assessment: Effectiveness Vs. Efficiency. 2013;9. Available from: http://stics.mruni.eu/wp-content/uploads/2013/06/45-53.pdf

8) Nigussa F. Cross country experience of Citizens' Charter implementation [Internet]. Devex. 2013 [cited 2022 Jan 30]. Available from: https://www.devex.com/news/sponsored/cross-country-experience-of-citizens-charterimplementation-81539

9) US Department of Housing and Urban Development. Improving performance with process mapping [Internet]. 2021 [cited 2021 Oct 30]. Available from: https://www.hudexchange.info/resource/4535/improving-performance-withprocess-mapping

10) Europian Union. Service standards [Internet]. Internal market, industry, entrepreneurship and SMEs. 2022 [cited 2022 Jan Available from: https://ec.europa.eu/growth/single-market/single-market-services/service-standards_en

11) Solutions \& Co. Services Standards - Levers of customer service quality [Internet]. Solutions \& Co. - Formations en entreprise. 2022 [cited 2022 Jan 29]. Available from: https://solutionsandco.com/blogue/newsletters-servicesstandardslevers-of-customer-service-quality 
Customer Satisfaction among Nursing Officers: Experience of Service Recipients at a District Health Office in Sri Lanka

12) Kotler P, Keller KL. Marketing management [Internet]. 14th [ed.]. Upper Saddle River, N.J: Prentice Hall; 2012.657 p. Available from: http://eprints.stiperdharmawacana.ac.id/24/1/\%5BPhillip_Kotler\%5D_Marketing_Management_14th_Edition\%28Book Fi\%2 9.pdf Attribution - Non Commercial 4.0 International (CC BY-NC 4.0)

(https://creativecommons.org/licenses/by-nc/4.0/), which permits remixing, adapting and building upon the work for non-commercial use, provided the original work is properly cited. 